Article

\title{
Less is More? Evaluating Technical Aspects and User Experiences of Smart Flood Risk Assessment Tools
}

\author{
Patrick A. Witte *, Karin A. W. Snel and Stan C. M. Geertman \\ Department of Human Geography and Planning, Utrecht University, The Netherlands; E-Mails: p.a.witte@uu.nl (P.A.W.), \\ k.a.w.snel@uu.nl (K.A.W.S.), s.c.m.geertman@uu.nl (S.C.M.G.) \\ * Corresponding author
}

Submitted: 6 March 2021 | Accepted: 19 April 2021 | Published: 19 August 2021

\begin{abstract}
In light of several recent large-scale flooding events worldwide, the urgency of involving residents in the flood risk management debate is growing. However, this has so far proven to be problematic, mainly because of lacking or ineffective communication between stakeholders. One way to better involve residents in the flood risk management debate is by developing smart applications, dedicated to facilitate and increase the insights of residents into the flood risk and vulnerability of their private properties. However, what is lacking thus far is a systematic evaluation of the technical aspects and the user experiences of such tools. The goal of this article is to explore and evaluate the technical, analytical, and communicative qualities of smart flood risk assessment tools. To this end, a new smart application named FLOODLABEL is used, aiming to inform residents of flood-prone areas about potential flood risks and associated protection measures of their dwellings. Based on this, the article concludes that a smart application like FLOODLABEL can be beneficial for informing residents about flood risks and potential protection measures. However, it also shows that a one-size-fits-all approach is not suitable for informing residents on flood risks, inter alia because how residents perceive risks is not homogeneous. This research is therefore just the first step towards a more systematic evaluation method of smart applications.
\end{abstract}

\section{Keywords}

flood risk governance; planning support; pluralism; risk communication; task-technology fit; user-technology fit

\section{Issue}

This article is part of the issue "Smart Urban Governance for Climate Change Adaptation" edited by Thomas Thaler (University of Natural Resources and Life Sciences, Austria), Patrick Witte (Utrecht University, The Netherlands), Thomas Hartmann (TU Dortmund University, Germany) and Stan Geertman (Utrecht University, The Netherlands).

(C) 2021 by the authors; licensee Cogitatio (Lisbon, Portugal). This article is licensed under a Creative Commons Attribution 4.0 International License (CC BY).

\section{Introduction}

Urban areas worldwide are facing increasing flood risks due to sea-level rise, increasing heavy rainfall, and rising groundwater levels. In light of several recent largescale flooding events worldwide, the growing insight is that traditional structural protection measures need to be complemented by non-structural measures, such as homeowners adapting their properties against flooding (Bradford et al., 2012; O'Neill et al., 2016). The background of this insight is the conviction that damage costs can be substantially reduced by increasing the flood resilience of individual buildings (Grothmann \& Reusswig, 2006; Kreibich et al., 2005). Structural protection measures have generally been a governmental task, yet the main actors in these non-structural measures are individuals. So, responsibilities concerning flood resilience are spreading from solely governmental organisations to include individual residents as well. This shift envisions more involvement of residents in the sense that they are expected to adjust their homes to prevent flood damage and to take responsibility in minimising the risk that their property might flood. 
However, so far this has proven problematic, in the sense that homeowners, in general, do not feel responsible or just feel partly responsible for taking flood protection measures (Bergsma et al., 2012). Even though information on flood risk and potential measures is generally available, homeowners are seldom aware of the urgency of flooding and often do not sufficiently prepare their properties or implement adaptation measures (Snel et al., 2019). Research shows that if Europeans would take flood adaptation measures, they could reduce the costs of flood damage by as much as $80 \%$ (Grothmann \& Reusswig, 2006). However, what homeowners perceive as their responsibility is of particular importance here. So far, it has proven difficult to increase homeowners' responsibility and involvement in flood risk governance. This can largely be attributed to the lack of effective communication between public administration, water management experts, and residents (Soane et al., 2010). Furthermore, existing barriers may stem from discussions on divisions of responsibility among stakeholders and discrepancies in the sense of urgency. For instance, in climate adaptation studies in general, it is concluded that the adaptive actions of residents are hindered because responsibilities are vague and ambiguous, which can lead to a lack of necessary adaptation (e.g., Runhaar et al., 2012). Additionally, residents tend to lack a sense of urgency with regards to taking flood adaptive actions (e.g., Kaufmann \& Wiering, 2019).

To improve communication on flood risk management, developing a smart application that facilitates residents' insight into flood risk and the vulnerability of private properties is a suitable way to provide flood risk information, like Floodtoolkit in the United Kingdom. This is a website with local information on flood risks, risk prevention responsibilities, flood protection measures, etc. (see, e.g., Oxfordshire County Council, n.d.). More recently, another smart application was launchedFLOODLABEL-aiming to inform residents in flood-prone areas about potential flood risks and the associated adaptation measures of their dwellings. Compared to the mentioned Floodtoolkit, FLOODLABEL (n.d.) indicates risks and potential measures at a much finer scale levelthe parcel. Nevertheless, in general, what has been lacking until now is a systematic evaluation of the technical aspects and the user experiences of such smart applications concerning flood risks. The goal of this article is to explore and evaluate the technical, analytical, and communicative qualities of smart flood risk assessment tools. We aim to evaluate how a smart application like FLOODLABEL, which is dedicated to communicating technical flood risk information, can be supportive for laymen in flood-prone areas in a technical, analytical, and communicative sense. This will be researched in the context of the Netherlands, a country in which flooding is a continuous risk, given the fact that a substantial part of the country is located below sea level.

\section{Literature Review}

\subsection{Plural Resident Perspectives in Flood Risk Management}

In present-day flood risk management, governmental agencies play a decisive role, both in the decisionmaking process (foremost intergovernmental) and in the implementation of decisions taken (e.g., Casiano \& Crompvoets, 2020; Mees et al., 2018). As a consequence, the communication of information is mostly performed in a one-directional and top-down manner: from foremost experts spanning from governmental organisations to the general public, i.e., laymen. However, when scientific (expert) information is communicated, e.g., about flood risks, laypeople mostly do not have the capabilities and/or knowledge to interpret the information as intended by the experts. Because of this gap between experts and laymen, the resulting behaviour of laymen is influenced accordingly (Dickson, 2005). Additionally, laymen's respective actions are not easy to influence, since their knowledge and perception is based on what information they already possess (lay knowledge) and receive by communication (Faulkner et al., 2010; Terpstra et al., 2009). As a consequence of insufficient expert-laymen communication, laymen will not always feel responsible for taking protection measures, e.g., to prevent and/or adapt to floods (Snel et al., 2019).

Although this one-directional and top-down risk communication model has been criticised for decades, flood risk communication has not yet fully distanced itself from it (Rollason et al., 2018). In flood risk management, the top-down communication orientation (from experts to laymen) is persistent with aims such as enhancing risk awareness, knowledge transfer, and giving subsequent advice to take action (Höppner et al., 2012). This is striking, since through the years it has been shown that the perception of (flood) risk is made up of various elements, including previous experiences, conversations with others (e.g., neighbours), culture, institutions, demography, and geography (e.g., Maidl \& Buchecker, 2015; Papagiannaki et al., 2019), which have hardly been considered in flood risk communication strategies until now.

Research by Snel et al. (2019) shows that the communication preferences of residents on flood risk communication are very diverse, implying that it is impossible to develop one standard communication method to inform and motivate all residents effectively. All respondents are willing to visit a website to inform themselves about flood risks, but a great variety of communication methods is needed to meet the diverse preferences of all residents, such as face-to-face communication, national campaigns and receiving flyers. Considering this, one can conclude that the "layman" does not exist as a label for an entire group of residents, but consists of different types of laymen, who all have different preferences for flood risk communication. Snel et al. (2019) 
define four groups through cultural theory (Douglas \& Wildavsky, 1983).

This theory identifies four distinct rationalities on which people base their perception of the world and by which their actions are determined: fatalism, hierarchism, individualism, and egalitarianism (Hartmann, 2012; Schwarz \& Thompson, 1990). These rationalities are portrayed in a matrix (Figure 1). Group represents the attachment to social values such as democracy, frequency of interaction, and equality, whereas grid represents the value of autonomy, control, and institutional integrity (Mamadouh, 1999). The position of the rationalities in the matrix represents the extent to which they associate with either strong or weak 'group' or 'grid' values.

In short, people with fatalistic rationality (weak group, strong grid) are characterised by the idea that the world and events cannot be controlled. The world can move freely both ways, and there is no "falling down" as shown in Figure 1 . The strong grid is externally determined, as it is not possible for individuals (i.e., weak group) to drastically influence it. Fatalism is overall a passive rationality. Hierarchists (strong group, strong grid) envision the world to be on top of a hill and in a small dip, which makes for a relatively robust equilibrium. This creates opportunities for trial and error, but only to a certain extent, as they do not want to destroy the equilibrium. They set up boundaries through rules and regulations, and hierarchy (strong grid). Additionally, they believe all members of society are equal and give power to an institution (strong group). Individualists (weak group, weak grid) have a robust worldview. Disturbances will only temporarily disrupt the equilibrium. Therefore, they can experiment, and each fault is also seen as an opportunity for benefit. Overall, self-determination and individual liberty are important values. Egalitarianists (weak

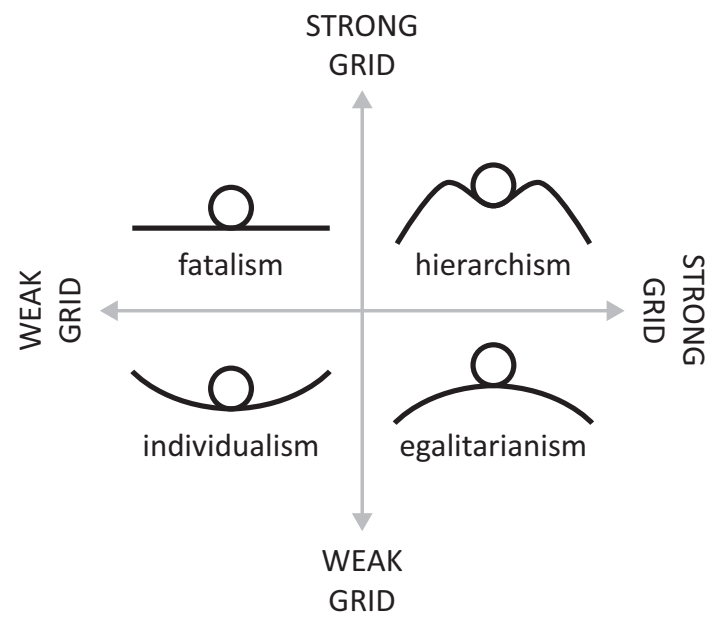

Figure 1. Group and grid diagram and pluralistic rationalities of cultural theory. Source: Authors based on Hartmann (2012), Schwarz and Thompson (1990), and Snel et al. (2019). grid, strong group) perceive the world to be on top of a hill, which causes such instability that already a small disturbance can destroy the equilibrium. Experimenting is very risky because failure means that the balance will be destroyed. They perceive the results of action as more important than the process (Hartmann, 2012; Schwarz \& Thompson, 1990; Snel et al., 2019).

The four groups are briefly described below based on their preferences for flood risk communication and link to the rationalities of cultural theory:

- Insusceptible confident (Fatalists): This group knows they are in danger but are not likely to act on this themselves because they believe their actions will not make a difference in case of a flood event. A website, face-to-face contact, expert advice, a television commercial, or a flyer are not preferred. The government should provide the public with flood risk information, i.e., they themselves take a passive role.

- Self-assured omniscient (Hierarchists): This group trusts in current flood risk management as done by the government. In other words, they trust in rules and regulations as outlined by the government, which is responsible for flood risk management in their eyes. They are not interested in expert advice, a detailed report or face-to-face communication. Rather they prefer a national campaign, i.e., a television commercial or flyers, and they need the government to stimulate them financially to take measures. This is the perspective that is mostly addressed in current flood risk communication.

- Acknowledged inexpert (Individualists): This group prefers face-to-face communication methods over a website. Ideally, they would like to be informed extensively by an expert, also about background information. This group is not a big advocate of a national campaign on flood risk or collaborations. They regard the individual residents as main actors responsible for protecting themselves against floods.

- Insufficiently connected (Egalitarianists): This group is most concerned about climate changeinduced floods, and therefore feel the need to take measures themselves. This group would like to obtain more information on what actual measures they can implement, and what the costs and benefits of these measures are. They prefer to use a website to obtain more of this information. Furthermore, this group would like to work together (community-based solutions) and they stand for common values and trust.

To enhance the action motivation of residents in floodprone areas, the intersubjectivity, and the sense of responsibility among individual residents, flood risk communication should address the above-mentioned plurality in its communicative approach (Snel et al., 2019). 
Besides pluralities in user preferences, the technical elements of flood risk communication remain important to be able to communicate the risks of flooding appropriately.

\subsection{Assessing Appropriate Characteristics of Smart Applications for Residents}

To evaluate smart applications for residents such as FLOODLABEL, use will be made of assessment criteria which are common practice in similar systems like Spatial Decision Support Systems (SDSS) and WebGIS applications. Janssen (1992) defines SDSS as a computer program that: (1) helps both individuals and groups making a decision; (2) supports (and does not replace) individuals' thoughts; and (3) enhances the effectiveness (instead of efficiency) of decision-making. In addition, Sugumaran and DeGroote (2010) indicate that SDSS must have sufficient analytical capabilities to process stakeholders' preferences, but also have an easy-to-use user interface, so communicative rationality capabilities should be part of the requirements too.

A focus on the laymen's interaction with a smart application is of particular interest here. Within the research field of WebGIS applications, the user perspective and the associated human-computer interaction are of prime importance. It is acknowledged that multiple users of an application differ in perspectives, needs, demands, etc. (Sluter et al., 2017) and these differences should be taken into consideration explicitly when assessing the quality of an application. Furthermore, besides the characteristics of the user (age, education, goals, etc.) and the qualities of the WebGIS product itself (e.g., functional suitability) in particular, the quality-in-use characteristics (i.e., human-computer interaction characteristics like efficiency and effectiveness) are also important in assessing the overall quality of a WebGIS application.

In 2017, we conducted a comparative study on likewise smart applications, foremost web-GIS applications, all heading to inform residents about the risks of flooding of their area/property (reported in Attems et al., 2020). The most important outcome of this comparison entails that, however useful such user-centred and participatory approaches may be, we still see a clear gap between informing homeowners about measures and them actually implementing the proposed measures. Based on these insights, the authors of this contribution developed, together with the Dutch firm Nelen and Schuurmans, the FLOODLABEL smart application, which was launched in 2020 (Utrecht University, 2020).

From the literature, several suggestions can be derived on how to optimise the human-computer interaction by taking into account distinctive user perspectives. First, Janssen and Uran (2003) found that in general the usage of maps and graphs is preferred over tables and text. Second, the level of detail affects the ability of users to successfully use the information. Third, the tim- ing in the process is important. According to Andrienko et al. (2003), visualisation should be considered in the phase where the options for a decision are evaluated and finally chosen. Fourth, the user, i.e., the layman, needs to be able to check what reasoning is used for a particular decision. To state it differently, the process in the sense of arguments, discussions, trade-offs, etc., that results in a particular decision should be sufficiently transparent.

From the above, it can be concluded that communication plays a prominent role in the interaction of expert knowledge to the layman user. As such, it needs to have a prominent place in a measurement framework of a smart application. Communicative support is given more meaning by not only focusing on the message but also on the target group (general public, laymen), the individual focus (individual risks and individual responsibilities), and the use of a combination of visualisation and non-visualisation/textual communication methods. Communicative support indicates whether the smart application is beneficial for the communication of information between all actors involved, which include both experts and a diverse group of laymen (Pelzer, 2017).

\section{Methodology and Data Collection}

\subsection{Methodological Approach}

This section operationalises how the smart application FLOODLABEL used in this research can support tasks technically and communicatively. Considering that residents usually make decisions without such a smart application, it is questioned whether residents are better informed about flood risks and the opportunities for adaptation measures when using the smart application FLOODLABEL, whether they are better able to make a well-informed decision, and whether they are motivated to implement this decision in the end. First, the technical/analytical support is analysed by examining the informative role of the tool for three aspects: (1) the informative role regarding flood impact in general; (2) the informative role regarding flood impact around the dwelling of the respondent; and ( 3 ) the informative role regarding potential measures to be taken to reduce the impact. The more respondents positively answer the statements about these three aspects, the better the analytical support. Second, the communicative support is determined by analysing statements that question whether certain parts of the tool are understandable, whether the entire tool is clear in terms of text and figures, whether the tool is easy to use and easy to understand, and whether it provides useful information on what happens behind the scenes. All combined answers to these statements make up the communicative support of the tool. Third, for the determination of the correct cultural theory perspective per respondent, distinct statements and interview questions are used to categorise the respondents into one of the four rationalities. 


\subsection{Data Collection and Analysis}

In this research, we made use of the smart application FLOODLABEL, a product outcome from the JPI Urban Europe research project FLOODLABEL. We made use of a two-step research process in conducting the empirical research. In the first step, we collected 109 respondents via door-to-door surveys with valid results combined over the three case studies (Dordrecht, Venlo, and Zwolle). Each respondent was asked to share his or her level of education (from basic education to university), age (mean age of 39 years old, youngest 18 years old while oldest 73 years old) and type of device used (most used a desktop or laptop, smaller amounts used a mobile phone or tablet), in combination with some general questions about the application. Then, in the second step, respondents out of the first group were asked whether they would be willing to participate in the indepth interview on the details of the application. In this second group, 17 in-depth interviews have been conducted, of which 6 in Zwolle, 7 in Dordrecht, and 4 in Venlo. The interviews lasted up to an hour. In this contribution, we focus on the 17 in-depth responses from the latter group.

The respondents were asked to use the FLOODLABEL website right before the interview to let them test it as if they were using it for their own dwelling. The interviewees were living in flood-prone areas that were predefined by the researchers to arrive at a preferred selection of interviewees. Furthermore, it was foremost due to the heavy demand we put on the respondents (asking them to make use of the website in advance and having them interviewed extensively thereafter) that the number of interviewees was not as high as expected at the start of the research. The themes of the interview itself were centred on analytical and communicative support (see Supplementary File). It is conceivable that only partial analytical or communicative support is found. It is thus examined how the tool performs analytically and communicatively among all respondents, and thus whether the smart application is optimally addressing the plural communication preferences of these residents.

\subsection{Case Studies and Respondents' Characteristics}

The smart application FLOODLABEL, based on its German analogue predecessor "the Hochwasserpass" (Hartmann \& Scheibel, 2016), generates for each Dutch premise the calculated flood risks and potential adaptation measures, including their effects on the recalculated flood risks. This is all based on geo-referenced data sets. Most relevant is the integrated map showing precipitation, river flooding, and groundwater information. On this map, the user can switch between different layers, zoom in and out, and navigate through the data. The risk calculation is divided into four types of flood risks: fluvial floods, pluvial floods, groundwater floods, and sewage flooding. This leads to one cumulative label ranging from green to red ( $A$ to $E$ ), indicating well-protected to vulnerable to flooding. For each of the specific types of floods a sublabel is indicated, also with a range of $A$ to $E$ (Figure 2a). Another feature of FLOODLABEL is that people can see what kind of measures they will have to take for their home to adapt to their flood risk. The range spans from simple preparations for flooding like moving valuable belongings from the ground floor to upper floors to more technical solutions like water protected windows to prevent floodwater from entering a house. Additionally, a differentiation is made between the short-term measures, like moving your car to a higher situated area, and long-term measures, like replacing the regular front door by one with better water resistance function (Figure $2 b$ ).

All respondents in the study are residents living in a flood-prone area. Zwolle, Venlo, and Dordrecht are chosen as case cities because of their geographical location within flood-prone areas (Figure 3). Furthermore, all three medium-sized cities are located in three geographically distinct areas in the country, representing the range of Dutch flood risks. Zwolle is located near the rivers IJssel and Vecht. The latter is a rain-fed river, whereas the IJssel is a tributary of the Rhine, which is a combination of a glacier-fed and rain-fed river. The residential areas in the city are susceptible to floods with a depth varying from 2 to 4 meters. Venlo is located in the southeast of the country, in the Meuse River basin at 20 to 35 meters above sea level. In 1993 and 1995 the area suffered two 1-in-200-year floods, which led to evacuations of the neighbourhoods alongside the river. Dordrecht is located in the southwest of the country. The city is an island surrounded by two major rivers: the Meuse and the Waal. In general, the city's land is 4 to 5 meters below sea level, but it is surrounded by a main dike ring protecting against a 1-in-1000-year (sea and river) flood. The three cities are chosen to be representative of flood risks in the entire country.

\section{Results}

\subsection{General Impression of the Tool}

Most respondents indicate that they are not concerned about the increasing risk of flooding to their home. Most of them did not worry, because they considered their location to be sufficiently safe. They state that they are aware of flood risk and substantiate their awareness with their living experience or their location concerning the rivers: "I am safe where I live, relatively new neighbourhood, 25 years old. The river is far away, there is a dike in between, so I am not concerned for the place where I live" (respondent 12). Several respondents did describe two sides of the story: "We are reasonably protected, we have it under control pretty well, we know what to do. Still, there is a chance that the water rises due to climate change" (respondent 16). Overall, respondents think their dwelling is safe because they do not expect a flood to happen in the short term. 


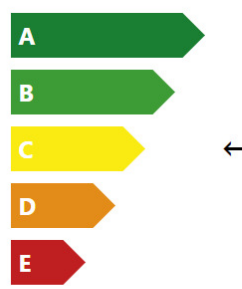

Floodlabel: $\mathrm{C}$

$U$ bent goed beschermd tegen de meeste typen overstromingen door de goede ligging van uw woning.

Dit is een voorlopig label gebaseerd op openbare data over de maximale waterdiepte per type overstroming. De kans dat deze overstroming plaatsvindt is niet meegenomen in het label. Klik verder om uw label aan te passen naar uw woning en om te kijken wat u zelf kunt doen voor uw veiligheid tegen water.
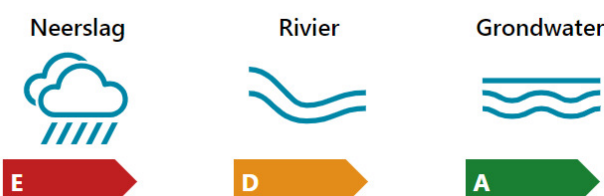

A

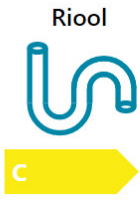

Uw omgeving

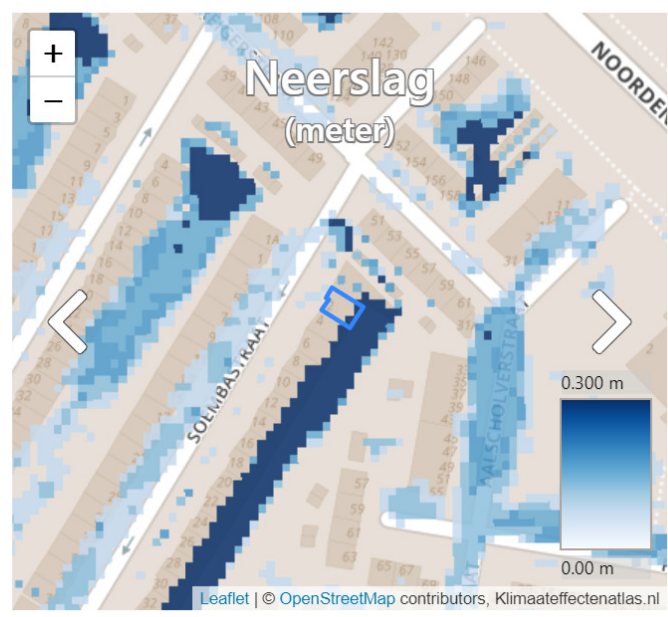

(a)

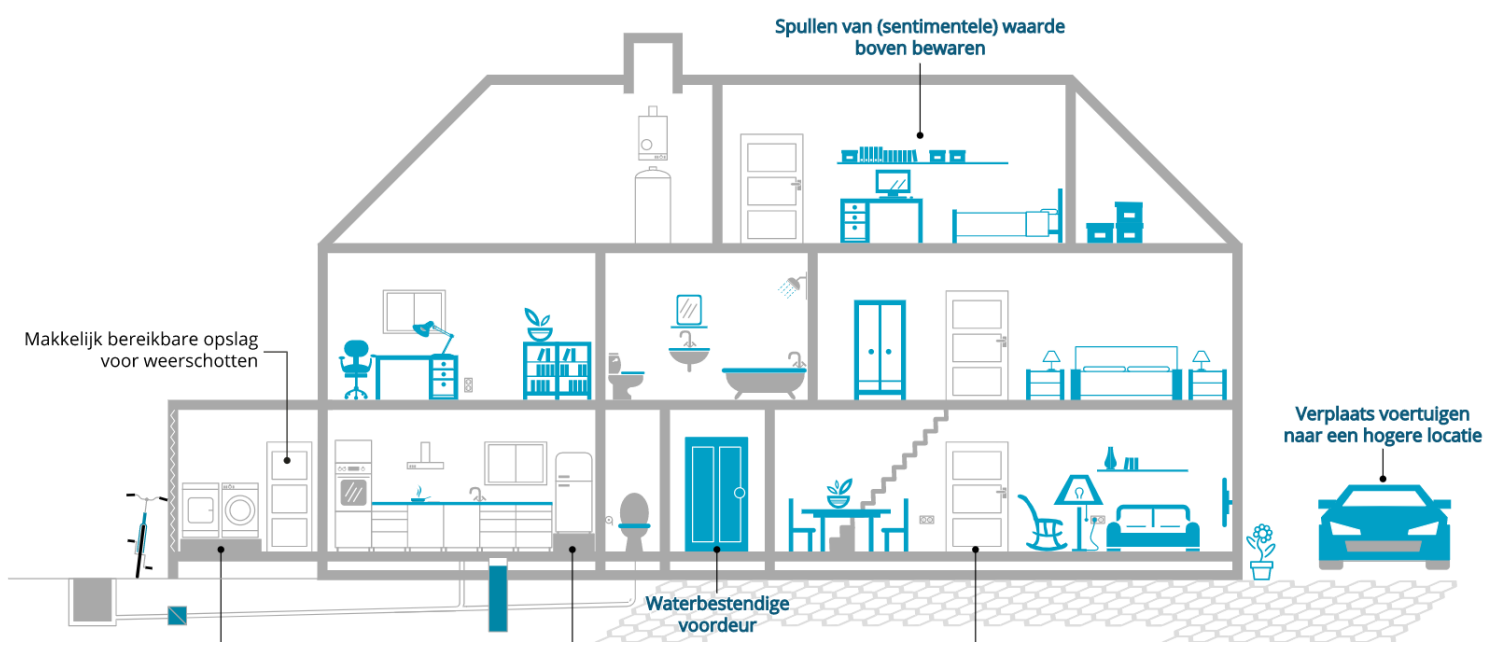

(b)

Figure 2. Screenshots from the FLOODLABEL application. (a) The left panel presents the flood label for different types of flooding (see symbols). The right panel shows the precipitation at the parcel level, but the user can also switch to the fluvial flooding or groundwater level maps. (b) The tool displays two figures for both short-term and long-term measures to implement in and around the house. On the website, below the figures, detailed information on each of the suggested measures is given. Source: FLOODLABEL (n.d.).

Although respondents are generally not concerned about flood risk, most of them are positive about the idea of a tool with personal flood risk information. Respondents who valued the smart application and its communicative function positively would like to additionally see another communication method (e.g., a flyer or television commercial) to lead them to the application. In other words, they indicated that they require a clear trigger to lead them to the smart application. Respondent 10 considers the tool more as a platform for real estate agents than for individual residents. Among those who are positive about the application, the statements "It is easy" and "I prefer doing this online and on my own" are the most common responses.

\subsection{Analytical Support Function of the Tool}

The valuation of the analytical support elements varies across the respondents. Generally, the informative role of the application is valued neither negatively nor 


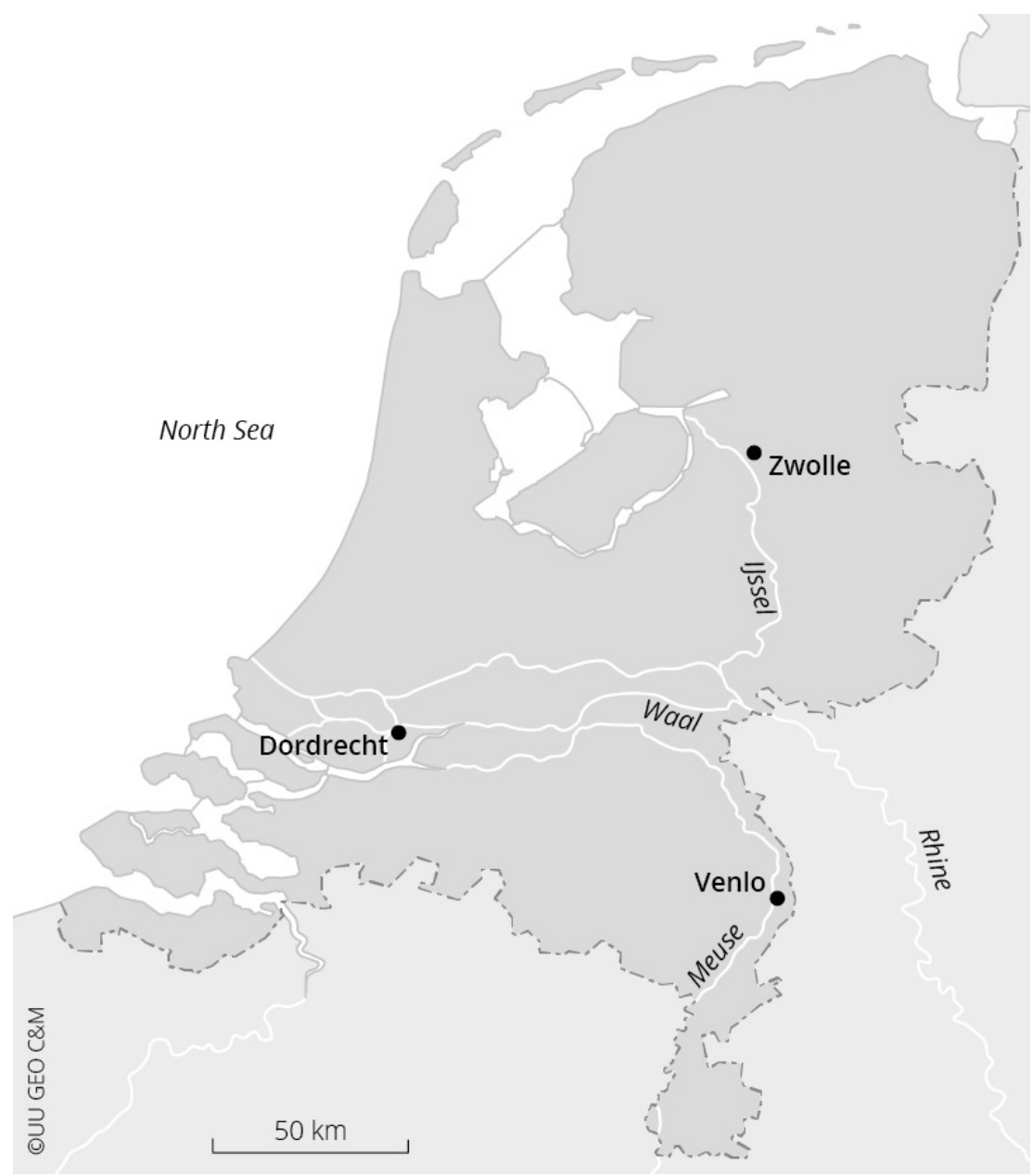

Figure 3. Case study locations within the Netherlands. Source: Snel et al. (2019).

positively. Only the different kinds of information are valued differently. The informative role of floods, in general, is valued more negatively than positively. Also, the informative role about flood impact specifically for the own dwelling of the respondent has more negative than positive answers. The informative role about potential measures is valued more positively, although nobody indicates that he or she is planning to actually implement any of the measures presented. In that sense, the analytical support can be considered as low. As respondent 12 states: "Beforehand I had no clue about flood risks, so compared to that I did get a little grasp from it, but I will not call myself an expert on floods, not at all."

The respondents from Venlo distinguished themselves from the respondents in Zwolle and Dordrecht. They all experienced the floods of 1993 and 1995, while the respondents from Zwolle and Dordrecht generally did not have any experience with floods at all. This leads to a totally different interpretation of the measures page. Where the respondents from Zwolle and Dordrecht were overall positive about the measures presented in the application, the respondents from Venlo found the measures inappropriate for the floods they experienced in 1993 and 1995. In other words, the measures proposed could be informative, but were in their particular case not appropriate to the scale of the floods that did occur. Respondents 15 and 17 illustrate the issue with the measures clearly:

You can purchase waterproof doors, you can insulate the walls, you can insulate the basement, but then still the water comes through those holes or it comes through the window. I had a water level of $1 \mathrm{~m} 12$, then it just comes through the window. There were measures you could actually implement, but I did not feel that it protected me in the end. (respondent 15)

Then you need totally different information.... For me, my dwelling is of importance. That is why you go to this website. Currently, I do not see any information that could have helped me in that situation. (respondent 17)

\subsection{Communicative Support Function of the Tool}

Communicative support is measured by ten statements about different parts of the smart application, plus additional questions. In terms of clarity, the potential measures are valued the most positively. All respondents were positive about the potential measures that were 
presented in the application. The most negatively judged is the statement "I can easily see what happens behind the scenes of the website." Most respondents also stated that they would like to see more of what happens in the background of the smart application to better comprehend the information presented.

Other results show that most respondents think that the application is easy-to-use and contains clear texts. The first part with the four flood labels is clear for most respondents, as is the extra information about the four types of floods. The questions about the own dwelling to specify the vulnerability to flooding are also clear. However, concerning the individuality of information (i.e., sufficiency of the level of detail per dwelling), there is no broad consensus among respondents. There is also no consensus about whether the application addresses individual responsibilities. It should be noted that, although the questions asked within the application were clear and comprehensible for most respondents, for many it was still unclear how to discover which measures they had already taken. For example, respondent 1 noted: "First, explain what a water barrier is, how you can get such a door, and how you can measure how high your front door is. These are the things you do not know."

\subsection{Plural Resident Perspectives on the Tool}

Comparing our findings to the plurality in residents' preferences as distinguished by Snel et al. (2019), we found that all four groups identified are slightly positive about the communicative support of the website, but they differ in degree. Of the 17 interviewees, two could be positioned in the first group (Fatalist), six in the second group (Hierarchist), four in the third group (Individualist), and five in the last group (Egalitarian).

First, the group of "insusceptible confident" (Fatalists) was slightly positive about the smart application FLOODLABEL, especially about the measures, the provided labels, and the extra information about the four flood types. They do not think that the smart application addresses individual responsibilities, i.e., it does not show what the responsibilities are of individual residents.

Second, the group of "self-assured omniscient" (Hierarchists) showed similar results, but ask for more clarity on the underlying reasons for the application: "You are confronted with all kinds of risks, but I think it is also good to explain in advance why you let people do that" (respondent 2). Also, this group asks for more specific information. Respondent 15, who experienced the 1993 and 1995 floods in Venlo, stated: "Because I experienced floods before, I do get the right information out of the website. Someone who has just moved here would perceive that differently. I think this information should be more specific." She added that the information should be even more specific for those dwellings that are located in the high flood risk area, i.e., right along the river Meuse.
Third, the group of "acknowledged inexpert" (Individualists) is the least positive about the communicative support of the smart application. What happens behind the scenes is not shown, while these respondents would like to see that. Also, this group does not agree with the statement that the application addresses individual responsibilities and that the information is communicated on an individual level. This group asks for more explanation across the entire smart application, for example for the map and for why a specific label is chosen. Some respondents in this group indicate that the application does not see a flood as a dynamic event (i.e., a "wave") but as a static thing. For instance, for a certain dwelling, the river label is "good," but when the dikes break and thus the impact is high, this information is very much misleading.

Fourth, the group of "insufficiently connected" (Egalitarians) is the most positive regarding the communicative support. They are most positive about the potential measures and least positive about whether what happens behind the scenes is shown. This group is also positive about whether the information is communicated at an individual level. Still, there are also critiques. Some respondents would also like to see the probability of flooding:

I miss a probability....Are we talking about once every ten years, once every 100 years, or once every 1000 years? The website says: In case of a flood, you are protected in these ways, but what is the probability of such a flood?....For me, this influences my feeling of urgency. (respondent 5)

Further, it is recommended that the inclusion of a source together with a probability would make the application much more reliable.

\subsection{Conclusion on the Tool's Support Function}

When asking whether the smart application raised respondents' awareness, the majority of the respondents answered positively. For those who have become more aware due to the application, most did not even think that a flood could happen near their home. All respondents from Venlo answered "no," as they already possessed a high awareness of flood risks due to previous experiences.

Even though respondents indicate a raised awareness of flood risk after using the application, this does not mean that they make plans to actually take action. This shows that based on the outcomes of the application, nobody is planning to implement flood adaption measures. Many respondents indicate there is no feeling of urgency and, as a consequence, they do not plan to take adaptive actions themselves. There is a distinction between the "bigger" and expensive measures (e.g., waterproof floors) and the "smaller" and cheaper investments (e.g., bring belongings of sentimental value to 
a higher floor). Respondents would consider the latter, only in some cases, for example when a severe flood is about to occur or has occurred already. None of the respondents seriously considered the large investments to protect their homes in the short term:

When it rains a lot, sometimes water does not flow into the garden. Something like that must happen and be even more extreme, making the water reach the house. Perhaps then you will really start to think about what you can adjust. But no, not at the moment. (respondent 12)

Looking at the differences between the four identified groups, both the insusceptible confidents and selfassured omniscient do not feel more responsible after making use of the application, which for them just partly raised awareness. "I do not think there are many flooding events in the Netherlands" (respondent 1) is an often-heard reason for why the application did not contribute to raising the respondents' awareness. Acknowledged non-experts show similar results to insusceptible confidents: Nobody feels more responsible for taking adaption/protection measures after making use of the application and only half of them showed increased awareness. A small majority of the group of insufficiently connected respondents feels more responsible for taking adaption measures after making use of the application. Most of them think their awareness has been raised due to the application, but, just as the other three groups, nobody is planning to actually take adaption measures. In the next section, the differences in flood risk awareness among different groups of residents are further discussed.

\section{Discussion, Conclusions, and Future Research}

\subsection{Discussion}

This research identified the existence of plural resident perspectives on flood risk communication and how this has a strong influence on how flood risk information should be communicated to residents, as also discussed by Snel et al. (2019). For example, some respondents, i.e., laymen, prefer flood probabilities as the main communication method (i.e., the "expert way" of communication, like for instance the chance of flooding as 1-in-10000 years), while other respondents have no clue what such probabilities entail. Also, responses vary based on whether respondents have had previous experiences with floods. To illustrate, since all respondents from Venlo have had experiences with the 1993 and 1995 floods, this influences their view on flood risk management and makes them probably more aware of what their flood risk is. Additionally, differences in the perceptions are also influenced by culture (e.g., political culture), institutions, demography (e.g., background in dealing with flooding), and geography (e.g., Faulkner et al., 2010; Maidl \& Buchecker, 2015).
Additional interesting differences can be found between the four identified groups of residents. According to Snel et al. (2019), acknowledged nonexperts are solely interested in their personal flood risks and the reasoning behind that. Since the FLOODLABEL application is developed as a platform to discover your personal flood risk, it was expected that this group would value the application positively. However, the results of this study showed otherwise. This group prefers the information to be much more specific for their own dwelling, while the other three groups consider the measures presented by the application to be of help in making informed decisions regarding flood adaptation. Currently, the background information about the data and content of the tool as presented by the application is uniform for all users. Therefore, due to the lack of tailored information on, e.g., the measures, the application is not a call-to-action for acknowledged non-experts, as it does not address their individual responsibilities.

Besides group differences regarding information preferences, uniform perspectives resulted in some issues as well. In the previous sections, it was indicated by Andrienko et al. (2003) that the user of a smart application needs to be able to check what reasoning or calculation is used for a particular decision, what factors are considered, what trade-offs are made, and thus how an application arrives at a certain decision. It can be observed that the smart application FLOODLABEL does not have the option to provide any insights into the calculations for the label allocation. Therefore, the respondents indeed collectively indicated that they want to see what happens behind the scenes of the application. The resulting labels and information presented are considered correct and informative, but provide insufficient insight into the process to arrive at a certain decision.

\subsection{Conclusions and Future Research Directions}

First, to fulfil the technical rationale of a smart application, FLOODLABEL should simply work and show the right information. Regarding this informative role, it can be stated that the application was considered insufficiently informative for flood risk information, concerning both flood risk information in general and residents' personal flood risk of their home. In contrast, the application showed to be mostly informative about potential effective adaption measures. In other words, the smart application FLOODLABEL is considered not entirely analytically supportive from a resident's (i.e., user) perspective.

Second, to fulfil the communicative rationale of a smart application, FLOODLABEL should provide clear and understandable information, targeted at the general public, showing what happens behind the scenes, communicating information on an individual level, addressing individual responsibilities, and using a combination of communication and visualisation methods. The empirical research shows that FLOODLABEL is clear in its presentation of adaption/protection measures; it is an 
application that is easy-to-use and the information communicated is clear. However, the application fails to provide insight into what is happening behind the scenes, while respondents indicate being very much interested in this kind of information.

In terms of future research, first, it shows there is a missing sense of urgency among many residents concerning flood risk information and adaptation. As climate change will likely increase the chance of flooding and its impact in the future, this missing sense of urgency needs to be addressed in flood risk communication. Second, it can be stated that the most challenging aspect of a smart application is to communicate flood risk information to residents while acknowledging the plurality of those residents' perspectives. These differences in preferences make it impossible to develop a uniform communication strategy that fulfils the wishes of all perspectives. As shown by Snel et al. (2019), current flood risk communication is mostly directed at self-assured omniscients, e.g., by using flood probabilities, and is thus not directed at all four perspectives. However, the probability-oriented communication method is insufficient in bringing all residents into action. Therefore, the other groups should be addressed in a better-targeted way too.

All in all, this article concludes that, on the one hand, a smart application like FLOODLABEL can be beneficial for informing residents about flood risks and potential adaption measures and in that better involving them as active stakeholders in the flood risk management debate. However, it also shows that a one-size-fits-all approach is not suitable for informing residents about flood risks, inter alia because how residents perceive risks is not homogeneous. Additionally, this article concludes that this research is just the first step towards a more systematic evaluation of smart applications in this research domain. As indicated, the number of respondents willing to test the smart application and be part of the semi-structured interviews was small. A much bigger research population would be needed to come up with firmer statements about their wishes and demands. Nevertheless, the research performed provides some valuable insights into the distinctive groups that can be identified based on cultural theory and how this relates to the issue of flood risk perception and opinions concerning willingness to take flood protection and adaption measures. Given the need for more awareness on flooding providing climate change developments, this kind of additional insight is urgently needed.

\section{Acknowledgments}

This study was supported by the ERA-NET Smart Urban Futures and Joint Programming Initiatives (JPI) Urban Europe; FLOODLABEL (Project No. 693443). The authors would like to thank Niels Venema and Danny van Hienen for their valuable contributions to the research underlying this article.

\section{Conflict of Interests}

The authors declare no conflict of interests.

\section{Supplementary Material}

Supplementary material for this article is available online in the format provided by the authors (unedited).

\section{References}

Andrienko, N., Andrienko, G., \& Gatalsky, P. (2003). Exploratory spatio-temporal visualization: An analytical review. Journal of Visual Languages \& Computing, 14(6), 503-541.

Attems, M. S., Thaler, T., Snel, K. A., Davids, P., Hartmann, T., \& Fuchs, S. (2020). The influence of tailored risk communication on individual adaptive behaviour. International Journal of Disaster Risk Reduction, 49, Article 101618.

Bergsma, E., Gupta, J., \& Jong, P. (2012). Does individual responsibility increase the adaptive capacity of society? The case of local water management in the Netherlands. Resources, Conservation and Recycling, $64,13-22$.

Bradford, R. A., O'Sullivan, J. J., Van Der Craats, I. M., Krywkow, J., Rotko, P., Aaltonen, J., \& Schelfaut, K. (2012). Risk perception-Issues for flood management in Europe. Natural Hazards and Earth System Sciences, 12(7), 2299-2309. https://doi.org/ 10.5194/nhess-12-2299-2012

Casiano, C., \& Crompvoets, J. (2020). Assessing the governance context support for creating a pluvial flood risk map with climate change scenarios: The Flemish subnational case. ISPRS International Journal of Geo-Information, 9(7), Article 460. https://doi.org/ 10.3390/ijgi9070460

Dickson, D. (2005, June 24). The case for a 'deficit model' of science communication. SciDev.Net. https://www.scidev.net/global/editorials/the-casefor-a-deficit-model-of-science-communic

Douglas, M., \& Wildavsky, A. (1983). Risk and culture: An essay on the selection of technological and environmental dangers. University of California Press.

Faulkner, H. P., Tunstall, S. M., \& McCarthy, S. (2010). Flood risk communication. In G. Pernder \& H. P. Faulkner (Eds.), Flood risk science and management (pp. 386-406). Wiley-Blackwell.

FLOODLABEL. (n.d.). Homepage. www.floodlabel.net

Grothmann, T., \& Reusswig, F. (2006). People at risk of flooding: Why some residents take precautionary action while others do not. Natural Hazards, 38(1), 101-120.

Hartmann, T. (2012). Wicked problems and clumsy solutions: Planning as expectation management. Planning Theory, 11(3), 242-256.

Hartmann, T., \& Scheibel, M. (2016). Flood Label for buildings $-A$ tool for more flood-resilient cities. E3S 
Web of Conferences, 7, Article 13006. https://doi. org/10.1051/e3sconf/20160713006

Höppner, C., Whittle, R., Bründl, M., \& Buchecker, M. (2012). Linking social capacities and risk communication in Europe: A gap between theory and practice? Natural hazards, 64(2), 1753-1778.

Janssen, R. (1992). Multiobjective decision support for environmental management. Springer.

Janssen, R., \& Uran, O. (2003). Presentation of information for spatial decision support: A survey on the use of maps by participants in quantitative water management in the IJsselmeer region, the Netherlands. Physics and Chemistry of the Earth, Parts $A / B / C$, 28(14/15), 611-620.

Kaufmann, M., \& Wiering, M. (2019). Dilemmas of an integrated multi-use climate adaptation project in the Netherlands: The Oekense Beek. In T. Hartmann, L. Slavíková, \& S. McCarthy (Eds.), Nature-based flood risk management on private land (pp. 193-207). Springer.

Kreibich, H., Thieken, A. H., Petrow, T., Müller, M., \& Merz, B. (2005). Flood loss reduction of private households due to building precautionary measures-Lessons learned from the Elbe flood in August 2002. Natural Hazards and Earth System Sciences, 5(1), 117-126.

Maidl, E., \& Buchecker, M. (2015). Raising risk preparedness by flood risk communication. Natural Hazards and Earth System Sciences, 15(7), 1577-1595.

Mamadouh, V. (1999). Grid-group cultural theory: An introduction. GeoJournal, 47(3), 395-409.

Mees, H., Crabbé, A., \& Suykens, C. (2018). Belgian flood risk governance: Explaining the dynamics within a fragmented governance arrangement. Journal of Flood Risk Management, 11(3), 271-280.

O’Neill, E., Brereton, F., Shahumyan, H., \& Clinch, J. P. (2016). The impact of perceived flood exposure on flood-risk perception: The role of distance. Risk Analysis, 36(11), 2158-2186. https://doi.org/10.1111/ risa. 12597

Oxfordshire County Council. (n.d.). Homepage. www. oxfordshirefloodtoolkit.com

Papagiannaki, K., Kotroni, V., Lagouvardos, K., \& Papagiannakis, G. (2019). How awareness and confidence affect flood-risk precautionary behavior of
Greek citizens: The role of perceptual and emotional mechanisms. Natural Hazards and Earth System Sciences, 19(7), 1329-1346. https://doi.org/10.5194/ nhess-19-1329-2019

Pelzer, P. (2017). Usefulness of planning support systems: A conceptual framework and an empirical illustration. Transportation Research Part A: Policy and Practice, 104, 84-95.

Rollason, E., Bracken, L. J., Hardy, R. J., \& Large, A. R. G. (2018). Rethinking flood risk communication. Natural Hazards, 92(3), 1665-1686.

Runhaar, H., Mees, H., Wardekker, A., Van Der Sluijs, J., \& Driessen, P. P. J. (2012). Adaptation to climate change-related risks in Dutch urban areas: Stimuli and barriers. Regional Environmental Change, 12, 777-790. https://doi.org/10.1007/s10113-0120292-7

Schwarz, M., \& Thompson, M. (1990). Divided we stand: Redefining politics, technology and social choice. University of Pennsylvania Press.

Sluter, C. R., van Elzakker, C. P., \& Ivanova, I. (2017). Requirements elicitation for geo-information solutions. The Cartographic Journal, 54(1), 77-90.

Snel, K. A., Witte, P. A., Hartmann, T., \& Geertman, S. C. (2019). More than a one-size-fits-all approach: Tailoring flood risk communication to plural residents' perspectives. Water International, 44(5), 554-570.

Soane, E., Schubert, I., Challenor, P., Lunn, R., Narendran, S., \& Pollard, S. (2010) Flood perception and mitigation: The role of severity, agency, and experience in purchase of flood protection, and the communication of flood information. Environment and Planning $A, 42$ (12), 3023-3038.

Sugumaran, R., \& DeGroote, J. (2010). Spatial decision support systems: Principles and practices. CRC Press.

Terpstra, T., Lindell, M. K., \& Gutteling, J. M. (2009). Does communicating (flood) risk affect (flood) risk perceptions? Results of a quasi-experimental study. Risk Analysis, 29(8), 1141-1155.

Utrecht University. (2020). FLOODLABEL: A smart tool for governance towards flood-resilient cities. https:// www.uu.nl/en/research/human-geography-andplanning/floodlabel-a-smart-tool-for-governancetowards-flood-resilient-cities

\section{About the Authors}

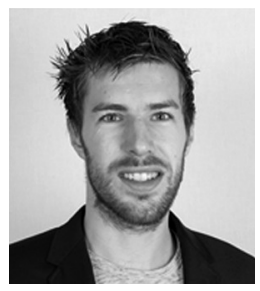

Patrick A. Witte (PhD) is Assistant Professor in Spatial Planning at Utrecht University. He is specialised in the interconnection of land use and transportation planning, with a particular focus on integrated corridor development and inland port development. He was the project coordinator of the JPI Urban Europe ENSUF project FLOODLABEL. His research interests are integrated spatial planning, transport infrastructure systems, transformations of cities, land use planning, and economic effects assessment. 


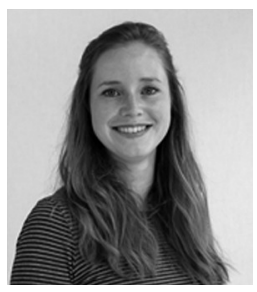

Karin A. W. Snel (MSc) is a Doctoral Student at Utrecht University. She has a background in anthropology and spatial planning. She was Project Officer on the JPI Urban Europe ENSUF project FLOODLABEL. Her research interests are urban planning, resilience and sustainability, flood risk management, and climate governance. She is currently finalising her doctoral dissertation on residents' involvement in flood risk governance.

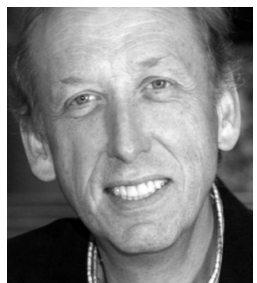

Stan C. M. Geertman (PhD) is Professor of Planning Support Science and Chair of Spatial Planning at Utrecht University. He has published widely in both national and international journals and has published a range of (editorial) books. He is Editor of the international peer-reviewed journal ASAP/Journal and Member of the editorial board of several other scientific journals. He has been a member of several international conference organisations. He was principal investigator of the JPI Urban Europe ENSUF project FLOODLABEL. 